\title{
Serum Hepcidin and Growth Differentiation Factor 15 In Patients with $\beta$ - thalassemia and Its Relation to Blood Transfusion
}

\author{
Mostafa Mahmoud Mahmoud Ghazala, ${ }^{4} \mathrm{MBBCh}$, Salama Saad Abdellateif, ${ }^{1} \mathrm{MD}$, Mostafa \\ Mohammed Shaban Taher, ${ }^{1}$ MD, Essam Ali Abdelmohsen, ${ }^{2}$ MD, Osama Hassan Bakheet, ${ }^{3}$ MD, \\ Ahmed Ali Ali Assem, ${ }^{1}$ MD
}

\section{* Corresponding Author:}

Mostafa Mahmoud Mahmoud Ghazala

mostafaghazala64@gmail.com Received for publication February 22, 2021; Accepted April 15, 2021; Published online April 15, 2021.

\section{Copyright 2020 The Authors published by Al-Azhar University, Faculty of Medicine, Cairo, Egypt. All rights reserved. This an open-access article distributed under the legal terms, where it is permissible to download and share the work provided it is properly cited. The work cannot be changed in any way or used commercially.}

doi: 10.21608/aimj.2021.64501.1422.

${ }^{1}$ Clinical Pathology Department, Faculty of Medicine, Al-Azhar University, Cairo, Egypt.

${ }^{2}$ Hematology Department, Armed Forces Hospitals, Cairo, Egypt.

${ }^{3 .}$ Clinical Pathology Department, Military Medical Academy, Cairo, Egypt.

${ }^{4}$ Clinical Pathology Department, Maadi Military Hospital, Cairo, Egypt.

\begin{abstract}
Background: Serum Hepcidin level drop is a main feature of chronic hemolytic anemia like $\beta$-thalassemia as an example. It is assumed that Hepcidin is influenced by anemia, iron overload due to repeated blood infusions and inflammation due to iron disposition in tissues.

Aim of the study: To measure plasma levels of the iron regulatory hormones; hepcidin and GDF-15 in $\beta$-thalassemic patients during intravenous blood infusion in order to assist clinical monitoring.

Patients and Methods: 30 cases previously diagnosed as a $\beta$ thalassemia major (group I) and 20 normal individuals of the same age and gender group (group II). The samples were collected immediately before and 8 days after transfusion. Hepcidin and GDF-15 levels were estimated using ELISA kit that is commercially available.

Results: As regard to serum Hepcidin level in both control and patient group was similar before the transfusion. The hepcidin level increased significantly after transfusion in both groups but in was significantly higher in patient group. $\mathrm{Hb}$ and hepcidin increased significantly posttransfusion. The pre- and post-transfusion hepcidin showed significant correlation with $\mathrm{Hb}$, Iron, and Ferritin in thalassemia patients. The pretransfusion Growth Differentiation Factor-15 was shooting in cases with $\beta$-thalassemia than presumably healthy control. The GDF-15 level decreased significantly after transfusion and it was significantly correlated with $\mathrm{Hb}$ and hepcidin levels.

Conclusion: Hepcidin serum level assessment can be used to monitor patients with iron-loading anemia and identify the patients prone to iron overload complications and iron toxicity.
\end{abstract}

Keywords: Thalassemia; Hepcidin; GDF-15.

Disclosure: The authors have no financial interest to declare in relation to the content of this article. The Article Processing Charge was paid for by the authors.

Authorship: All authors have a substantial contribution to the article.

\section{INTRODUCTION}

Thalassemia occurs due to defective hemoglobin protein spatial shapes due to imbalanced protein chains representation, specifically $\beta$-globin deficiency, due to genetic defect. ${ }^{1} \beta$-thalassemia become more sever with more decreased formation or absence of $\beta$ - chain. ${ }^{2}$

Regarding geographical distribution of $\beta$ thalassemia, it prevails more in countries on the Mediterranean, South east of Asia and in the east of Europe. In Egypt, it is the most common cause of chronic blood loss: One thousand cases are recorded annually for every 1.5 million live births the disease prevalence is equal to1000 cases per 1.5 million live births. $^{3}$
The clinical manifestations of beta-thalassemia varies greatly from mild form of chronic anemia to severe recurrent anemia and infections and this is influenced by many different factors like gene level and function, levels of different types of globin chains, presence of modifiers and environmental factors. ${ }^{4}$

In our study, we classified thalassemic cases into two groups according to frequency of blood transfusion. 1-TDT (transfusion dependent thalassemia), those cases require blood infusion as the cornerstone of treatment because they suffer severe red blood cell hemolysis like cases with homozygous beta globin 
chain loss and 2-NTDT (non-transfusion dependent thalassemia). ${ }^{5}$

Increased serum Iron is the main cause of the manifestations of thalassemia even in patients with occasional blood transfusion. Iron absorption, transport and storage is regulated by the hormone hepcidin. Hepcidin is hepatic peptide. ${ }^{6}$

Hepcidin is inhibited by erythropoiesis by a negative feedback mechanism. And this explains Hepcidin deficiency in cases maintained on blood transfusion and receives no oral iron because the anemic state and increased bone morrow red blood synthesis will inhibit Hepcidin production and consequently hyper oral iron absorption. ${ }^{7}$

However, the exact pathophysiology of Hepcidin deficiency in thalassemia is still unknown. The theory of messenger molecule secreted from bone marrow to suppress Hepcidin remains the best theory. GDF-15, is increased in thalassemia and has inhibitory effect on hepcidin secretion in vitro. ${ }^{8}$

Previous studies showed a relation between pre- and post-transfusion hepcidin levels and anemia, RBCs synthesis, serum iron level and inflammation. In other words, blood transfusion in thalassemia cases lead to higher Hepcidin level. Transfusion mediates erythropoietic hyperplasia, which in turn raises Hepcidin production. ${ }^{9}$

\section{PATIENTS AND METHODS}

The study was designed to be of a non-randomized observational study. Where 50 adult individuals who came to the hematology section in Maadi military hospital in the period from the 1st of June 2019 to the 1st of June 2020.

They have been classified into: Group (1): includes 30 adult patients with TDT and divided into two subgroups: Group 1A: included 30 adult patients with TDT immediately prior to transfusion\& Group 1B: included the same 30 adult patients with TDT eight days following transfusion. Group (2): includes 20 non $\beta$-thalassemia patients that will be selected randomly from presumably healthy population, sex and age matched. All subjects were informed and gave written consents.

Inclusion criteria: adult patients of both sexes with transfusion-dependent $\beta$-thalassemia. Exclusion criteria patients suffering from: Other types of anemia other than beta-thalassemia.

Complete history was taken and clinical assessment was done to all participants. Laboratory investigations including: (serum ALT - serum AST), (serum Urea - serum Creatinine), CBC, Hemoglobin electrophoresis, Reticulocyte count, Iron profile (Iron - Ferritin - TIBC) and C-reactive protein. And special tests: Serum Hepcidin and Serum GDF-15.
From each control and patients, $10 \mathrm{ml}$ of venous blood was withdrawn, $4 \mathrm{ml}$ blood in EDTA vacutainer tube for $\mathrm{CBC}$, reticulocyte count and hemoglobin electrophoresis. $6 \mathrm{ml}$ blood in plain vacutainer tube was left for clotting, then centrifuged, separated serum divided in 2 aliquots, 3 $\mathrm{ml}$ for routine chemical investigations and Iron profile (Iron - Ferritin - TIBC) and C-reactive protein and $3 \mathrm{ml}$ frozen at $-80 \mathrm{C}$ and used for hepcidin and GDF-15 assay using (ELISA) kits.

\section{Statistics:}

Data were examined and interpreted using (SPSS) software. Many tests were done: Independentsamples t-test of significance, Chi-square test and Pearson's correlation coefficient (r) test. Quantitative data were expressed as mean \pm standard deviation (SD). Qualitative data were expressed as number and percentage.

Probability (P-value): P-value $<0.05$ was considered significant, $\mathrm{P}$-value $<0.001$ was considered as highly significant and $\mathrm{P}$-value $>0.05$ was considered insignificant.

\section{RESULTS}

The characteristics for the studied group cases (19 males and 31 females) are shown in table (1). This table shows: No statistically significant difference (pvalue $>0.05$ ) between studied groups (group I and group II) as regard age \& sex; Statistically significant difference ( $\mathrm{p}$-value $<0.05$ ) between studied groups (group I and group II) as regard height; and Highly statistically significant difference (p-value $<0.001$ ) between studied groups (group I and group II) as regard weight. As regard days since last transfusion, the mean in studied patients' group was $20.73 \pm 1.2$ days with minimum days of 18 days and maximum days of 24 days. As regard mean age of transfused units (days), the mean in studied patients' group was $11.8 \pm 2.2$ days with minimum days of 10 days and maximum days of 16 days.

As regard S. ferritin, there was highly significant increase in S. Ferritin in group (I) patients with a mean of $(1613.8 \pm 994.9)$ in comparison to control group with a mean of (43.4 \pm 16.9$)$. No statistically significant difference (p-value $>0.05$ ) between studied groups (group I and group II) as regard Urea, Creat, and CRP.

As regard serum hepcidin, there was no significant difference in S. hepcidin level in group (I) patients with a mean of (25.2 \pm 14.7$)$ in comparison to control group with a mean of $(20.8 \pm 2.1)$.

As regard GDF-15, there was highly significant increase in S. GDF-15 in group (I) patients with a mean of $(6945.7 \pm 1035)$ in comparison to control group with a mean of $(398.2 \pm 180.8)$. 


\begin{tabular}{|c|c|c|c|c|c|c|c|}
\hline \multicolumn{2}{|c|}{ Demographic data } & \multicolumn{2}{|c|}{$\begin{array}{l}\text { Group I } \\
(\mathbf{N}=\mathbf{3 0})\end{array}$} & \multicolumn{2}{|c|}{$\begin{array}{l}\text { Group II } \\
(\mathbf{N}=20)\end{array}$} & Stat. test & P-value \\
\hline \multirow{2}{*}{ Gender } & Male & 12 & $40 \%$ & 7 & $35 \%$ & \multirow{2}{*}{$X^{2}=0.12$} & \multirow{2}{*}{$0.721 \mathrm{NS}$} \\
\hline & Female & 18 & $60 \%$ & 13 & $65 \%$ & & \\
\hline \multirow{2}{*}{ Age (years) } & Mean \pm SD & \multicolumn{2}{|c|}{$28.9 \pm 2.7$} & \multicolumn{2}{|c|}{$29.4 \pm 3.1$} & \multirow{2}{*}{$\mathrm{MW}=275$} & \multirow{2}{*}{0.618 NS } \\
\hline & Median & 29 & & 30 & & & \\
\hline \multirow{2}{*}{ Weight (kg) } & Mean \pm SD & \multirow{2}{*}{\multicolumn{2}{|c|}{$\begin{array}{l}59.8 \pm 5.6 \\
61.5\end{array}$}} & \multicolumn{2}{|c|}{$71.1 \pm 9.5$} & \multirow{2}{*}{$\mathrm{T}=5.2$} & \multirow{2}{*}{$<0.001$ HS } \\
\hline & Median & & & 69 & & & \\
\hline \multirow{2}{*}{ Height (cm) } & Mean \pm SD & \multirow{2}{*}{\multicolumn{2}{|c|}{$\begin{array}{l}159.9 \pm 7.6 \\
156\end{array}$}} & \multirow{2}{*}{\multicolumn{2}{|c|}{$\begin{array}{l}167.4 \pm 9.4 \\
164.5\end{array}$}} & \multirow{2}{*}{ MW12 = 167} & \multirow{2}{*}{$0.008 \mathrm{~S}$} \\
\hline & Median & & & & & & \\
\hline
\end{tabular}

Table 1: Comparison between studied groups as regard demographic data. (T: independent sample T test; HS: pvalue $<0.001$ is considered highly significant; NS: $\mathrm{p}$-value $>0.05$ is considered non-significant).

\begin{tabular}{|c|c|c|c|c|c|}
\hline \multicolumn{2}{|l|}{ Laboratory data } & $\begin{array}{l}\text { Group I } \\
(\mathbf{N}=\mathbf{3 0})\end{array}$ & $\begin{array}{l}\text { Group II } \\
(\mathbf{N}=20)\end{array}$ & Stat. test & P-value \\
\hline \multirow{2}{*}{ Hb (g/dl) } & Mean \pm SD & $6.4 \pm 0.5$ & $13.5 \pm 0.8$ & \multirow{2}{*}{$T=39.1$} & \multirow{2}{*}{$<0.001$ HS } \\
\hline & Median & 6.3 & 13.5 & & \\
\hline \multirow{2}{*}{ Urea (mg/dl) } & Mean \pm SD & $28.8 \pm 3.4$ & $27.3 \pm 3.4$ & \multirow{2}{*}{$\mathrm{T}=1.5$} & \multirow{2}{*}{$0.127 \mathrm{NS}$} \\
\hline & Median & 29.5 & 24 & & \\
\hline \multirow{2}{*}{ Creat (mg/dl) } & Mean \pm SD & $0.51 \pm 0.08$ & $0.53 \pm 0.11$ & \multirow{2}{*}{$\mathrm{MW}=279.5$} & \multirow{2}{*}{$0.671 \mathrm{NS}$} \\
\hline & Median & 0.5 & 0.5 & & \\
\hline \multirow{2}{*}{ SGPT (U/L) } & Mean \pm SD & $51.5 \pm 28.5$ & $24.5 \pm 3.9$ & \multirow{2}{*}{ MW $=141.5$} & \multirow{2}{*}{$0.002 \mathrm{~S}$} \\
\hline & Median & 46 & 24 & & \\
\hline \multirow{2}{*}{ SGOT (U/L) } & Mean \pm SD & $91.9 \pm 52.7$ & $21.4 \pm 4.7$ & \multirow{2}{*}{$\mathrm{MW}=1.5$} & \multirow{2}{*}{$<0.001 \mathrm{HS}$} \\
\hline & Median & 65 & 19.5 & & \\
\hline \multirow{2}{*}{ Retics (\%) } & Mean \pm SD & $6.08 \pm 1.05$ & $0.57 \pm 0.16$ & \multirow{2}{*}{$\mathbf{M W}=\mathbf{0 . 0}$} & \multirow{2}{*}{$<0.001$ HS } \\
\hline & Median & 6 & 0.5 & & \\
\hline \multirow{2}{*}{ CRP (mg/L) } & Mean \pm SD & $1.8 \pm 1.04$ & $2.07 \pm 0.8$ & \multirow{2}{*}{$\mathrm{T}=0.98$} & \multirow{2}{*}{$0.329 \mathrm{NS}$} \\
\hline & Median & 1.6 & 2.1 & & \\
\hline \multirow{2}{*}{ Iron (ug/dl) } & Mean \pm SD & $236.2 \pm 49.3$ & $58.2 \pm 7.8$ & \multirow{2}{*}{$\mathbf{M W}=\mathbf{0 . 0}$} & \multirow{2}{*}{$<0.001$ HS } \\
\hline & Median & 220 & 58.5 & & \\
\hline \multirow{2}{*}{ Ferritin (ng/ml) } & Mean \pm SD & $1613.8 \pm 994.9$ & $43.4 \pm 16.9$ & \multirow{2}{*}{ MW $=\mathbf{0 . 0}$} & \multirow{2}{*}{$<0.001$ HS } \\
\hline & Median & 1451.5 & 35 & & \\
\hline \multirow{2}{*}{ TIBC (ug/dl) } & Mean \pm SD & $234.7 \pm 12.4$ & $331.5 \pm 27$ & \multirow{2}{*}{$\mathbf{M W}=\mathbf{0 . 0}$} & \multirow{2}{*}{$<0.001$ HS } \\
\hline & Median & 239.5 & 334.5 & & \\
\hline \multirow{2}{*}{ GDF-15 (pg/ml) } & Mean \pm SD & $6945.7 \pm 1035$ & $398.2 \pm 180.8$ & \multirow{2}{*}{$\mathrm{MW}=\mathbf{0 . 0}$} & \multirow{2}{*}{$<0.001 \mathrm{HS}$} \\
\hline & Median & 5950 & 347.5 & & \\
\hline & Mean \pm SD & $25.2 \pm 14.7$ & $20.8 \pm 2.1$ & $\mathrm{MW}=229$ & $0160 \mathrm{NS}$ \\
\hline Hepcidin (ng/ml) & Median & 24 & 20 & $\mathrm{MW}=229.5$ & \\
\hline
\end{tabular}

Table 2: Comparison between studied groups (I \& II) as regard laboratory data. (T: independent sample T test; HS: p-value $<0.001$ is considered highly significant; NS: p-value $>0.05$ is considered non-significant).

To evaluate the direct effect of transfusion on hepcidin level, iron indices, laboratory investigations were determined in group (1A) patients (pretransfusion) and compared with those of group (1B) patients (post-transfusion) as shown in table (3).

Serum hepcidin levels were significantly increased from $(25.2 \pm 14.7)$ to $(54.6 \pm 31.03)$ with P-value < 0.001 HS. Serum GDF-15 were decreased from $(6945.7 \pm 1035)$ to $(4417.5 \pm 1363)$ with significant improvement of serum ferritin from (1613.8 \pm 994.9) to $(2463.6 \pm 1919)$. (Figure 1$)$.

Also, serum iron was significantly increased from $(236.2 \pm 49.3)$ to $(264.1 \pm 54)$. There was significant improvement of $\mathrm{Hb}$ concentration from $(6.4 \pm 0.5)$ to $(7.8 \pm 0.6)$.

The study showed that there were statistically significant negative correlations (p-value $>0.05$ ) between hepcidin and weight, height, reticulocyte count, TIBC, and GDF-15 in thalassemia patients. Statistically significant positive correlations ( $\mathrm{p}$-value $<0.05$ ) between hepcidin and $\mathrm{Hb}$, Iron, and Ferritin in thalassemia patients 


\begin{tabular}{|c|c|c|c|c|c|}
\hline \multicolumn{2}{|l|}{ Laboratory data } & $\begin{array}{l}\text { Group IA } \\
(\mathrm{N}=30)\end{array}$ & $\begin{array}{l}\text { Group IB } \\
(\mathbf{N}=\mathbf{3 0})\end{array}$ & MW & P-value \\
\hline \multirow{2}{*}{ Hb (g/dl) } & Mean \pm SD & $6.4 \pm 0.5$ & $7.8 \pm 0.6$ & \multirow{2}{*}{15.5} & \multirow{2}{*}{$<0.001 \mathrm{HS}$} \\
\hline & Median & 6.3 & 7.8 & & \\
\hline \multirow{2}{*}{ Urea (mg/dl) } & Mean \pm SD & $28.8 \pm 3.4$ & $29.2 \pm 3.1$ & \multirow{2}{*}{431} & \multirow{2}{*}{$0.777 \mathrm{NS}$} \\
\hline & Median & 29.5 & 30 & & \\
\hline \multirow{2}{*}{ Creat (mg/dl) } & Mean \pm SD & $0.51 \pm 0.08$ & $0.51 \pm 0.1$ & \multirow{2}{*}{435} & \multirow{2}{*}{$0.813 \mathrm{NS}$} \\
\hline & Median & 0.5 & 0.5 & & \\
\hline \multirow{2}{*}{ SGPT (U/L) } & Mean \pm SD & $51.5 \pm 28.5$ & $52.9 \pm 28.7$ & \multirow{2}{*}{440.5} & \multirow{2}{*}{$0.888 \mathrm{NS}$} \\
\hline & Median & 46 & 45 & & \\
\hline \multirow{2}{*}{ SGOT (U/L) } & Mean \pm SD & $91.9 \pm 52.7$ & $95.2 \pm 54.4$ & \multirow{2}{*}{422.5} & \multirow{2}{*}{$0.684 \mathrm{NS}$} \\
\hline & Median & 65 & 66.5 & & \\
\hline \multirow{2}{*}{ Retics (\%) } & Mean \pm SD & $6.08 \pm 1.05$ & $6.6 \pm 0.7$ & \multirow{2}{*}{320} & \multirow{2}{*}{$0.053 \mathrm{NS}$} \\
\hline & Median & 6 & 6.5 & & \\
\hline \multirow{2}{*}{ CRP (mg/L) } & Mean \pm SD & $1.8 \pm 1.04$ & $1.9 \pm 1.1$ & \multirow{2}{*}{417.5} & \multirow[b]{2}{*}{$0.630 \mathrm{NS}$} \\
\hline & Median & 1.6 & 1.9 & & \\
\hline \multirow{2}{*}{ Iron (ug/dl) } & Mean \pm SD & $236.2 \pm 49.3$ & $264.1 \pm 54$ & \multirow{2}{*}{305.5} & \multirow{2}{*}{$0.033 \mathrm{~S}$} \\
\hline & Median & 220 & 256.5 & & \\
\hline \multirow{2}{*}{ Ferritin (ng/ml) } & Mean \pm SD & $1613.8 \pm 994.9$ & $2463.6 \pm 1919$ & \multirow{2}{*}{299} & \multirow{2}{*}{$0.026 \mathrm{~S}$} \\
\hline & Median & 1451.5 & 2251 & & \\
\hline \multirow{2}{*}{ TIBC (ug/dl) } & Mean \pm SD & $234.7 \pm 12.4$ & $224.7 \pm 15.2$ & \multirow{2}{*}{253.5} & \multirow{2}{*}{$0.004 \mathrm{~S}$} \\
\hline & Median & 239.5 & 227.5 & & \\
\hline \multirow{2}{*}{ GDF-15 (pg/ml) } & Mean \pm SD & $6945.7 \pm 1035$ & $4417.5 \pm 1363$ & \multirow{2}{*}{190} & \multirow{2}{*}{$<0.001 \mathrm{HS}$} \\
\hline & Median & 5950 & 3897.5 & & \\
\hline Honcidin (n & Mean \pm SD & $25.2 \pm 14.7$ & $54.6 \pm 31.03$ & 104 & $<00014$ \\
\hline Hepcidin (ng/ml) & Median & 24 & 55.5 & 184 & $<0.001 \mathrm{HS}$ \\
\hline
\end{tabular}

Table 3: Comparison between studied groups (I \& II) as regard laboratory data. (T: independent sample T test; S: p-value $<0.05$ is considered significant; HS: p-value $<0.001$ is considered highly significant; NS: p-value $>0.05$ is considered non-significant).
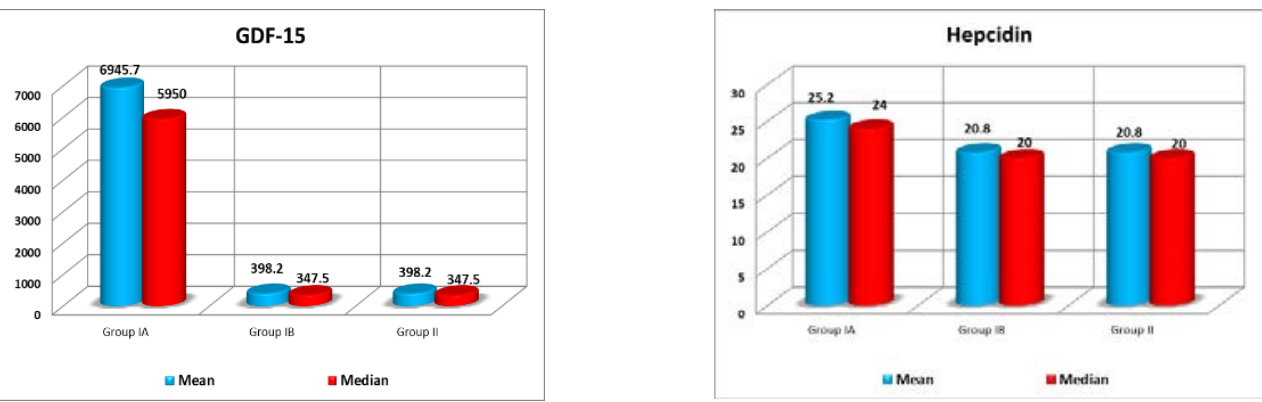

Fig 1:. Comparison between studied groups as regard GDF-15 and Hepcidin.

\begin{tabular}{|c|c|c|c|c|c|c|}
\hline \multirow{2}{*}{ Hepcidin Correlations } & \multicolumn{2}{|c|}{ Group IA } & \multicolumn{2}{|c|}{ Group IB } & \multicolumn{2}{|c|}{ Group II } \\
\hline & (r) & p-value & (r) & p-value & (r) & p-value \\
\hline Age & 0.25 & 0.183 NS & 0.21 & $0.262 \mathrm{NS}$ & 0.36 & $0.124 \mathrm{NS}$ \\
\hline Weight & -0.44 & $0.015 \mathrm{~S}$ & -0.45 & $0.012 \mathrm{~S}$ & 0.15 & $0.542 \mathrm{NS}$ \\
\hline Height & -0.74 & $<0.001 \mathrm{HS}$ & -0.77 & $<0.001$ HS & -0.09 & $0.696 \mathrm{NS}$ \\
\hline Hb & 0.49 & $0.005 \mathrm{~S}$ & 0.39 & $0.031 \mathrm{~S}$ & -0.14 & $0.543 \mathrm{NS}$ \\
\hline Urea & 0.01 & $0.956 \mathrm{NS}$ & 0.30 & $0.113 \mathrm{NS}$ & -0.36 & $0.123 \mathrm{NS}$ \\
\hline Creat & 0.31 & $0.1 \mathrm{NS}$ & 0.04 & $0.826 \mathrm{NS}$ & -0.25 & $0.288 \mathrm{NS}$ \\
\hline SGPT & 0.25 & $0.191 \mathrm{NS}$ & 0.24 & $0.196 \mathrm{NS}$ & 0.33 & $0.16 \mathrm{NS}$ \\
\hline SGOT & 0.28 & $0.13 \mathrm{NS}$ & 0.26 & $0.171 \mathrm{NS}$ & -0.15 & $0.543 \mathrm{NS}$ \\
\hline Retics & -0.56 & $0.001 \mathrm{~S}$ & -0.68 & $<0.001$ HS & -0.03 & $0.895 \mathrm{NS}$ \\
\hline CRP & 0.009 & $0.961 \mathrm{NS}$ & 0.006 & $0.997 \mathrm{NS}$ & -0.17 & $0.486 \mathrm{NS}$ \\
\hline Iron & 0.40 & $0.029 \mathrm{~S}$ & 0.55 & 0.002 S & -0.18 & $0.448 \mathrm{NS}$ \\
\hline Ferritin & 0.37 & $0.043 \mathrm{~S}$ & 0.39 & 0.032 S & -0.09 & $0.717 \mathrm{NS}$ \\
\hline TIBC & -0.37 & $0.004 \mathrm{~S}$ & -0.4 & 0.025 S & 0.08 & $0.729 \mathrm{NS}$ \\
\hline GDF-15 & -0.49 & $0.006 \mathrm{~S}$ & -0.63 & $<0.001$ HS & 0.16 & $0.499 \mathrm{NS}$ \\
\hline
\end{tabular}


Table 4: Correlation study between Hepcidin and other studied parameters in studied groups. ((r): Pearson correlation coefficient.; S: p-value $<0.05$ is considered significant; HS: p-value $<0.001$ is considered highly significant; NS: p-value $>0.05$ is considered non-significant).

\section{DISCUSSION}

The Beta-Thalassemia Major is a genetic chronic hemolytic anemia associated with ineffective erythropoiesis and peripheral hemolysis resulting in severe form of anemia. There is strong inhibitory effect of erythropoiesis on Hepcidin secretion in cases of Beta-thalassemia. ${ }^{10}$

The excessive dietary iron absorption in these patients accompanied There is a severe increase in iron content in blood and other tissues of cases of chronic hemolytic anemia which is the major cause of mortality and morbidity due to increased oral iron absorption in addition to repeated packed red blood cell infusion especially in TDT(transfusion dependent thalassemia. ${ }^{11}$

Previous studies have showed that pre- and posttransfusion hepcidin levels correlated with anemia, erythropoiesis, iron loading and inflammation. Transfusion mediates erythropoietic hyperplasia, which in turn raises hepcidin production. Studies found that hepcidin levels in patients with $\beta$ thalassemia major were associated with anemia, erythropoiesis, and iron stores; that suppression of erythropoiesis by transfusion is associated with an increase in hepcidin. ${ }^{9}$

Nevertheless, there is a scarcity in the published literature that aims to determine whether, in $\beta$ thalassemia major, transfusion-mediated inhibition of erythropoiesis dynamically affects hepcidin. Thus, we conducted the present case-control study in order to assess serum level of the iron regulatory hormones; hepcidin and GDF-15 in patients with $\beta$ thalassemia and its relation to blood transfusion in order to assist clinical monitoring.

In the current study we found that patients with thalassemia major had lower hemoglobin level and higher HbF. This agreed with, Ayyash ${ }^{12}$ they reported that patients with thalassemia had statistically significant lower hemoglobin level, RBCs count, hematocrit value, mean corpuscular hemoglobin concentration, and higher $\mathrm{HbF}$.

In this study, the serum level of ferritin, total iron significantly higher in patients with $\beta$-thalassemia major. This indicates the high iron overload in the studied patients. This was in agreement with Mishra $\mathrm{AK}^{13}$ assessed the serum ferritin levels in multitransfused thalassemia major and thalassemia intermediate patients.

This study found that the pre-transfusion hepcidin level was decreased and the hepcidin level increased significantly post-transfusion. The pre-and posttransfusion Hepcidin level was directly proportional to $\mathrm{Hb}$ and ferritin, iron and inversely proportional to erythropoiesis.

One possible explanation for inhibition of Hepcidin in cases with Beta-thalassemia and other conditions with increased erythropoiesis is that there is erythropoiesis associated signal that prevents Hepcidin secretion. An extract from blood of cases with thalassemia could prevent HAMP release in liver cells in vitro, this proves presence of serum signaling which can overcome iron over load signaling. ${ }^{14}$

Suppression of Hepcidin in chronic anemia can be dependent on erythropoietin. Rats with induced anemia require an active erythroid component to inhibit liver Hepcidin. Hypoxia does not inhibit Hepcidin if Erythropoietin hormone-mediated erythropoiesis is inhibited. ${ }^{14}$

This experiment used blood infusion to treat anemia, suppress erythropoiesis, and increase Hepcidin.

In agreement with this findings, Pasricha ${ }^{9}$ evaluated serum Hepcidin in Beta-thalassemic cases pre- and post-transfusion, Regarding erythropoiesis and iron metabolism. Post transfusion, hemoglobin and hepcidin increased. Pre-transfusion Hepcidin was directly proportional to hemoglobin and ferritin and inversely proportional erythropoiesis.

Kearney ${ }^{15}$ aimed to estimate levels of hepcidin in cases with congenital chronic anemia. 49 cases with anemia, varying degrees of erythropoiesis and iron burden were recruited. In thalassemia major, hepcidin levels markedly elevated post transfusion and demonstrated wide variance.

Camberlein ${ }^{16}$ described similar results using Hepcidin mRNA by PCR technique when he showed lower mRNA hepcidin in thalassemia group after transfusion.

Kemna $^{17}$ estimated transferrin saturation (TS), soluble transferrin receptor (sTfR), and C-reactive protein (CRP) along with Hepcidin and pro-Hepcidin and compared the results between cases with iron overload and normal individuals. He proved that sTfR there is strong correlation between sTfR and erythropoiesis that inhibited the iron storage regulation of Hepcidin.

This study found that the pre-transfusion GDF-15 was significantly higher in patients with $\beta$ thalassemia and the GDF-15 level decreased significantly after transfusion. The pre- and posttransfusion GDF-15 correlated significantly with $\mathrm{Hb}$ and hepcidin level.

Likewise, Pasricha ${ }^{9}$ showed that the post-transfusion, GDF-15 decreased significantly. Pre-transfusion GDF-15 was inversely correlated with hepcidin.

Yumei Huang ${ }^{18}$ described much high levels of GDF15 in cases with TDT. A reciprocal relation was observed between GDF-15 and Hepcidin among thalassemic cases, thus, it is possible that GDF-15 over-expression suppresses Hepcidin, contributing to iron disposition in body tissues in thalassemic cases. 
Further studies are needed to examine this hypothesis.

Other described an increase in GDF-15 levels in patients with P.K. enzyme deficiency, multiple myeloma, and anemia. However, GDF-15 levels significantly higher in ßeta-thalassemia patients and in some cases, GDF-15 expression was inversely proportional to Hepcidin levels. ${ }^{19}$

GDF-15 may be a biomarker for evaluating erythropoiesis in both qualitative and quantitative ways. So we can estimate future transfusion dosing and frequency. Future studies can be directed to clarify the role of Hepcidin and GDF-15 in erythropoiesis. We proved a correlation between Hepcidin and Erythropoiesis as an Iron loading signal so estimation of Hepcidin and GDF-15 may be useful in giving us clear idea about the current state of iron and erythropoiesis in patient's body.

\section{CONCLUSION}

Decreased serum level of Hepcidin is the main manifestation of iron overload in $\beta$ eta-thalassemia which could have been caused by a strong inhibitory effect of erythropoietic activity signals on Hepcidin secretion. The management of $\beta$-thalassemia by tradition involves avoiding the adverse outcomes of disease using transfusion therapy. Hepcidin serum level assessment can be used to monitor patients with iron-loading anemia and identify the patients prone to iron overload complications and iron toxicity.

\section{REFERENCES}

1. Lee YK, Kim HJ, Lee K, et al. Recent progress in laboratory diagnosis of thalassemia and hemoglobinopathy: A study by the Korean Red Blood Cell Disorder Working Party of the Korean Society of Hematology. Blood Res. 2019;54:17-22.

2. Turner M, Deshpande S, Chitnis M, et al. A Global Systematic Literature Review on the Burden of Illness in Transfusion-Dependent $\beta$-Thalassemia. Blood. 2019;134:5786.

3. Eissa D and El-Gamal R. Iron overload in transfusion-dependent $\beta$-thalassemia patients: defining parameters of comorbidities. Egypt $J$ Haematol. 2014;39:164.

4. Chuncharunee S, Teawtrakul N, Siritanaratkul N, et al. Review of disease-related complications and management in adult patients with thalassemia: A multi-center study in Thailand. PLoS One. 2019;14:214148.

5. Motta I, Bou-Fakhredin R, Taher AT, et al. Beta Thalassemia: New Therapeutic Options Beyond Transfusion and Iron Chelation. Drugs [Internet]. 2020;1-11.

6. Camaschella C, Nai A and Silvestri L. Iron metabolism and iron disorders revisited in the hepcidin era. Haematologica. 2020;105:260-72.

7. Zarghamian P, Azarkeivan A, Arabkhazaeli A, et al. Hepcidin gene polymorphisms and iron overload in $\beta$-thalassemia major patients refractory to iron chelating therapy. BMC Med Genet. 2020;21:1-5.

8. Wischhusen J, Melero I and Fridman WH. Growth/Differentiation Factor-15 (GDF-15): From
Biomarker to Novel Targetable Immune Checkpoint. Vol. 11, Frontiers in Immunology. 2020;11: 951.

9. Pasricha SR, Frazer DM, Bowden DK, et al. Transfusion suppresses erythropoiesis and increases hepcidin in adult patients with $\beta$-thalassemia major: A longitudinal study. Blood. 2013;122:124-33.

10. Roy CN, Mak HH, Akpan I, et al. Hepcidin antimicrobial peptide transgenic mice exhibit features of the anemia of inflammation. Blood. 2007;109:4038-44.

11. Tanno T, Bhanu N V., Oneal PA, et al. High levels of GDF15 in thalassemia suppress expression of the iron regulatory protein hepcidin. Nat Med. 2007;13:1096-101.

12. Ayyash $\mathrm{H}$ and Sirdah M. Hematological and biochemical evaluation of $\beta$-thalassemia major $(\beta \mathrm{TM})$ patients in Gaza Strip: A cross-sectional study. Int J Health Sci (Qassim). 2018;12:18-24.

13. Mishra AK and Tiwari A. Iron overload in Beta thalassaemia major and intermedia patients. Maedica (Buchar) [Internet]. 2013;8:328-32.

14. Nemeth E. Hepcidin and beta-thalassemia major. Blood. 2013;122:3-4.

15. Kearney SL, Nemeth E, Neufeld EJ, et al. Urinary hepcidin in congenital chronic anemias. Pediatr Blood Cancer. 2007;48:57-63.

16. Camberlein E, Zanninelli G, Détivaud L, et al. Anemia in $\beta$-thalassemia patients targets hepatic hepcidin transcript levels independently of iron metabolism genes controlling hepcidin expression. Haematologica. 2008;93:111-5.

17. Kemna EHJM, Kartikasari AER, van Tits LJH, et al. Regulation of hepcidin: insights from biochemical analyses on human serum samples. Blood Cells $\mathrm{Mol}$ Dis. 2008;40:339-46.

18. Huang Y, Lei Y, Liu R, et al. Imbalance of erythropoiesis and iron metabolism in patients with thalassemia. Int J Med Sci. 2019;16:302-10.

19. Rishi G and Subramaniam VN. The relationship between systemic iron homeostasis and erythropoiesis. Biosci Rep. 2017;37:1-7. 